ARTICLE

DOI: $10.1038 / s 41467-018-07593-0$

\title{
Selective production of phase-separable product from a mixture of biomass-derived aqueous oxygenates
}

Yehong Wang (iD ${ }^{1}$, Mi Peng ${ }^{2}$, Jian Zhang ${ }^{1}$, Zhixin Zhang ${ }^{1}$, Jinghua $A n^{1,3}$, Shuyan u $^{1}$, Hongyu An ${ }^{1,3}$, Fengtao Fan ${ }^{1}$, Xi Liu (D) ${ }^{4,5}$, Peng Zhai ${ }^{2}$, Ding Ma ${ }^{2}{ }^{2} \&$ Feng Wang $^{1}$

Selective conversion of an aqueous solution of mixed oxygenates produced by biomass fermentation to a value-added single product is pivotal for commercially viable biomass utilization. However, the efficiency and selectivity of the transformation remains a great challenge. Herein, we present a strategy capable of transforming $70 \%$ of carbon in an aqueous fermentation mixture ( $\mathrm{ABE}$ : acetone-butanol-ethanol-water) to 4-heptanone (4HPO), catalyzed by tin-doped ceria (Sn-ceria), with a selectivity as high as $86 \%$. Water (up to $27 \mathrm{wt} \%$ ), detrimental to the reported catalysts for $A B E$ conversion, was beneficial for producing 4-HPO, highlighting the feasibility of the current reaction system. In a $300 \mathrm{~h}$ continuous reaction over $2 \mathrm{wt} \% \mathrm{Sn}$-ceria catalyst, the average 4-HPO selectivity is maintained at $85 \%$ with $50 \%$ conversion and $>90 \%$ carbon balance. This strategy offers a route for highly efficient organic-carbon utilization, which can potentially integrate biological and chemical catalysis platforms for the robust and highly selective production of value-added chemicals.

\footnotetext{
${ }^{1}$ State Key Laboratory of Catalysis, Dalian National Laboratory for Clean Energy, Dalian Institute of Chemical Physics, Chinese Academy of Sciences, Dalian 116023, China. ${ }^{2}$ College of Chemistry and Molecular Engineering and College of Engineering, BIC-ESAT, Peking University, Beijing 100871, China. ${ }^{3}$ University of Chinese Academy of Sciences, Beijing 100049, China. ${ }^{4}$ State Key Laboratory of Coal Conversion, Institute of Coal Chemistry, Chinese Academy of Sciences, Taiyuan, Shanxi 030001, China. ${ }^{5}$ Syncat@Beijing, SynfuelsChina Co. Ltd, Beijing 101407, China. Correspondence and requests for materials should be addressed to D.M. (email: dma@pku.edu.cn) or F.W. (email: wangfeng@dicp.ac.cn)
} 
W ith the development of sustainable energy and chemicals, interest in fermentation processes is reviving, because they can transform non-edible biomass feedstock to low-molecular-weight oxygenates, such as acetone, nbutanol, and ethanol in the acetone-butanol-ethanol-water (ABE) fermentation broth ${ }^{1,2}$. The crude fermentation broth contains low concentrations of oxygenates, which can be enriched by specific techniques such as pervaporation, gas stripping, and adsorption. However, the complexity/cost of the purification process limits its widespread practical applications. Thus, finding a method to directly and selectively convert crude aqueous oxygenate mixture to value-added chemicals, especially waterimmiscible ones, thus allowing easy separation after reaction, is of great importance.

The efficiency and selectivity of the transformation process for biomass-derived intermediates remains a major techno-economic challenge $^{3}$. Significantly, carbon-carbon coupling enables the conversion of small intermediate molecules to larger ones, which is critical for fuel production ${ }^{4-7}$. However, carbon-carbon crosscoupling between oxygenates is complicated. For homogeneous catalysts, although high yield can be achieved, the separation of the catalyst after reaction is difficult ${ }^{8,9}$. For heterogeneous catalysts, the selectivities for certain reactions are rather $\operatorname{low}^{10}$ and both types of catalysts demand high purity of feedstock ${ }^{11}$, which is a major obstacle to industrialization of biomass conversion. In $\mathrm{ABE}$ fermentation broth conversion, deprotonation of the $\mathrm{C}-\mathrm{H}$ group at the a-positions of the primary products, including acetone, acetaldehyde, and butanal is not selective. Enolate intermediates generated in the process react with aldehyde or ketone to produce a randomly distributed ketone mixture with carbon number ranging from 5 to 11 , which is ideal for fuel production but not enough for single chemical fabrication. Moreover, the presence of large amount of water deactivates the reported catalytic system in aqueous $\mathrm{ABE}$ solution ${ }^{12}$. It is pivotal to develop a highly efficient water-resistant catalyst for the direct conversion of crude aqueous oxygenate mixture.

Herein we report a simple reaction for the conversion of aqueous ABE fermentation broth, containing acetone, $n$-butanol, ethanol, acetic acid, and butyric acid to a water-immiscible product efficiently and selectively. Catalyzed by $\mathrm{Sn}$-ceria catalyst, the biomass-derived oxygenates mixture was transformed to 4heptanone (4-HPO) (a flexible precursor for the synthesis of various value-added chemicals or fuels (Supplementary Figure 1 and Supplementary Table 1)) with selectivity as high as $86 \%$. A series of characterizations verified the importance of highly dispersed tin oxide and oxygen vacancies in the selective production of 4-HPO from the $\mathrm{ABE}$ mixture. A biomass conversion route to transform low-quality biomass fermentation broth to easily separable value-added product was constructed using this strategy, thereby greatly reducing process complexity.

\section{Results and Discussion}

Catalytic results. First, a mixture of acetone, $n$-butanol, ethanol, and water in a f:51:1:22 ratio (by weight) was fed into a vertical fixed-bed reactor loaded with a ceria catalyst, which was prepared by a precipitation method ${ }^{13}$. Liquid products were collected using a cold-trap. Carbon balance, conversion, yield, and selectivity were calculated based on carbon number of each molecule, as per the following equations (see Supplementary Figure 2 and Supplementary Table 2).

$$
\begin{gathered}
\text { Carbon balance }(\%)=\frac{n(\mathrm{c})_{\text {gas }}+n(\mathrm{c})_{\text {liquid }}}{n(\mathrm{c})_{\text {feed }}} \times 100 \% \\
\text { Conversion }(\%)= \\
\frac{n(\mathrm{c})_{\text {feed }}-n(\mathrm{c})_{\text {liquid, butanol }}-n(\mathrm{c})_{\text {liquid, ethanol }}-n(\mathrm{c})_{\text {liquid, acetone }}}{n(\mathrm{c})_{\text {feed }}} \times 100 \% \\
\text { Yield }(\%)=\frac{n(\mathrm{c})_{4-\mathrm{HPO}}}{n(\mathrm{c})_{\text {feed }}} \times 100 \% \\
\text { Selectivity }(4-\mathrm{HPO})(\%)= \\
\frac{n(\mathrm{c})_{4-\mathrm{HPO}}}{n(\mathrm{c})_{\text {gas }}+n(\mathrm{c})_{\text {liquid }}-n(\mathrm{c})_{\text {liquid, butanol }}-n(\mathrm{c})_{\text {liquid, ethanol }}-n(\mathrm{c})_{\text {liquid, acetone }}} \times 100 \%
\end{gathered}
$$

where $n(\mathrm{c})_{4-\mathrm{HPO}}$ is the number of moles of carbon atoms in 4 HPO, $n(c)_{\text {feed }}$ is the number of moles of carbon atoms in the feedstock, and $n(\mathrm{c})_{\text {liquid }}$ is the number of moles of carbon atoms in the liquid trapped in the tank, including products and unreacted feedstock. The terms $n(\mathrm{c})_{\text {liquid, butanol }}, n(\mathrm{c})_{\text {liquid, acetone, }}$ and $n(\mathrm{c})_{\text {liquid, ethanol }}$ represent the number of moles of carbon atoms of $n$-butanol, acetone, and ethanol, respectively, trapped in the liquid. The terms $n(c)_{\text {gas }}$ is the number of moles of carbon atoms in gaseous products.

When the reaction was conducted at $400-420^{\circ} \mathrm{C}$ over ceria catalyst, the liquid-phase product naturally separates into two layers: the lightyellow upper layer is the oil phase and the colorless bottom layer is the

\begin{tabular}{|c|c|c|c|c|c|c|c|c|}
\hline Catalyst & C balance $(\%)$ & Conv. (\%) & 4-HPO yield (\%) & \multicolumn{5}{|c|}{ Liquid product distribution (\%) } \\
\hline _- & 100 & - & - & - & - & - & - & - \\
\hline Sn-Ceria & 106 & 71 & 61 & 86 & 3 & 3 & 3 & 5 \\
\hline Zn-Ceria & 100 & 95 & 59 & 73 & 27 & - & - & - \\
\hline Fe-Ceria & 92 & 95 & 57 & 75 & 25 & - & - & - \\
\hline Sn-Ceria[c] & 108 & 82 & 59 & 72 & 22 & - & 5 & 1 \\
\hline Sn-Ceria ${ }^{[d]}$ & 105 & 72 & 45 & 63 & 29 & - & 6 & 2 \\
\hline
\end{tabular}
aqueous phase. The oil phase was found to consist of 78\% 4-HPO and $15 \%$ 2-pentanone, whereas in the aqueous phase mainly unreacted acetone and water were detected. In the gas phase, $<4 \% \mathrm{CO}_{2}$ was detected, demonstrating that most of the converted reactants have

Table 1 Conversion of aqueous ABE solution over various catalysts ${ }^{[a]}$

[a] Reaction conditions: $3.2 \mathrm{~g}$ of catalyst (40-60 mesh), pretreated in $\mathrm{H}_{2}\left(15 \mathrm{~mL} \mathrm{~min}^{-1}\right)$ at $420^{\circ} \mathrm{C}$ for $1 \mathrm{~h}$ and then the reaction was conducted at $420{ }^{\circ} \mathrm{C}$ for $2 \mathrm{~h}$; the $\mathrm{A}: \mathrm{B}: \mathrm{E}$ weight ratio is $9: 51: 1$, the water content is $27 \mathrm{wt} \%$, weight hourly space velocities (WHSV) $=0.5 \mathrm{~h}^{-1} ; \mathrm{N}_{2}$ as carrier gas (flow rate $=10 \mathrm{~mL} \mathrm{~min}^{-1}$ ), the content of $\mathrm{Zn}$, Fe, or In in doped ceria is 2 wt\%. [b] A:B:E weight ratio is $3: 6: 1$, the water content is $21 \mathrm{wt} \%$. [c] The A:B:E weight ratio is 1:5.7:1.2, the water content is $20 \mathrm{wt} \%$. [d] The A:B:E weight ratio is 1.7:4:1, the water content is 20 wt\%. BAL butanal, BBA butyl butyrate, 2-HPO 2heptanone, 4-HPO 4-heptanone, PNO 2-pentanone 
been fixed into liquid products. For comparison, no product was obtained in the uncatalyzed reaction (Table 1).

Reaction pathways. The reaction with pure oxygenate mixture without water was studied. Interestingly, the selectivity of 4-HPO decreased from $84 \%$ to $31 \%$ together with a decrease of conversion from $22 \%$ to $10 \%$, suggesting that water is critical for the highly selective synthesis of 4-HPO in this system. (Fig. 1(a, b)). This also holds when using pure $n$-butanol or $n$-butanol/water as the feed (Supplementary Figure 3). Significantly, with $n$-butanol/ water as the feed, 4-HPO was proposed to be produced by the following steps (Supplementary Figure 4): (i) dehydrogenation of $n$-butanol to butanal and hydrogen, (ii) esterification of butanol and butanal to butyl butyrate and hydrogen, (iii) reduction of
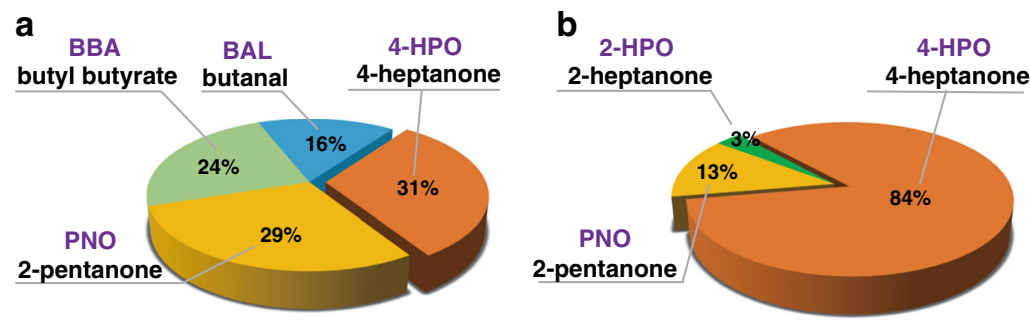

C

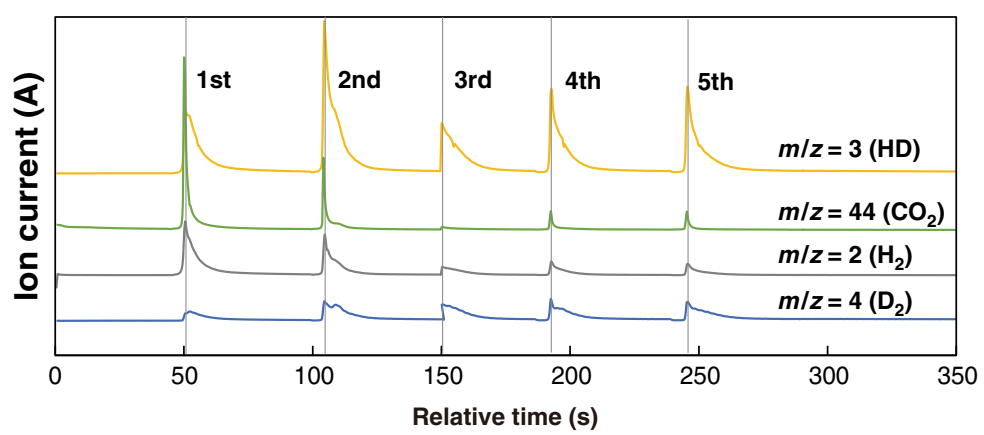

d
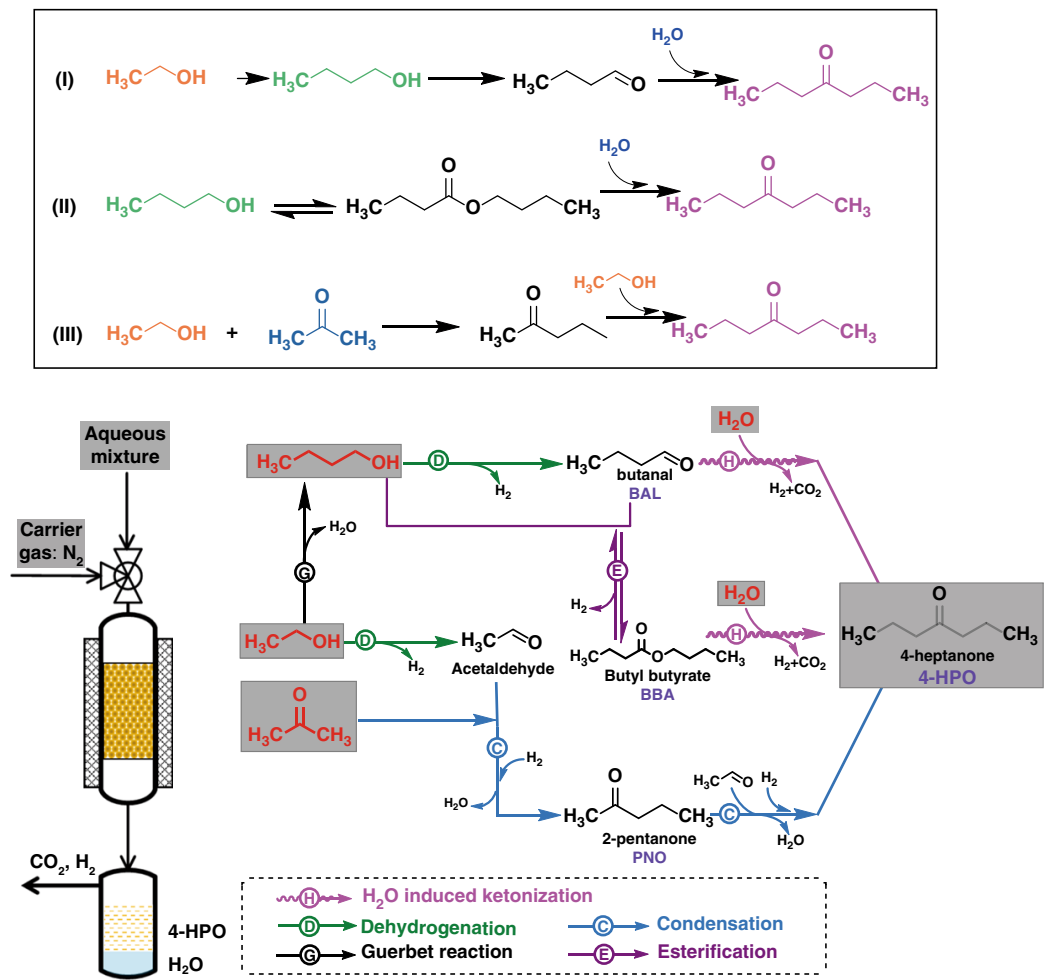

Fig. 1 The catalytic function of water in $A B E$ aqueous solution conversion reaction and proposed reaction pathways. a $A B E$ as feedstock ( $A: B: E$ weight ratio is 9:51:1). b ABE with water as feedstock ( $A: B: E: H_{2} \mathrm{O}$ weight ratio is 9:51:1:22). Reaction conditions: ceria (16.0 g, 14-25 mesh), $\mathrm{N}_{2}$ as carrier gas (flow rate $=33 \mathrm{~mL} \mathrm{~min}-1), 400^{\circ} \mathrm{C}, \mathrm{WHSV}=0.5 \mathrm{~h}^{-1}$. c Pulse reaction of a mixture of $n$-butanol and $\mathrm{D}_{2} \mathrm{O}$ (detected by on-line mass spectrometry). Ceria ( $1.0 \mathrm{~g}$, 14-25 mesh), $10 \mu \mathrm{L}$ per injection of $n$-butanol and $\mathrm{D}_{2} \mathrm{O}$ mixture, Ar as carrier gas (flow rate $=30 \mathrm{~mL} \mathrm{~min}{ }^{-1}$ ), $400{ }^{\circ} \mathrm{C}$. The fluctuation of each pulse is due to non-uniform sampling of butanol for each injection (from butanol/ $\mathrm{D}_{2} \mathrm{O}$ emulsion mixture). $\mathbf{d}$ Proposed reaction pathways leading to 4-HPO in a fixed-bed reactor with acetone, $n$-butanol, ethanol, and water as feedstock over ceria-based catalyst 
a

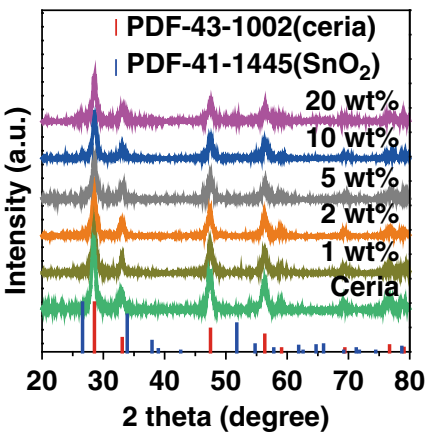

b

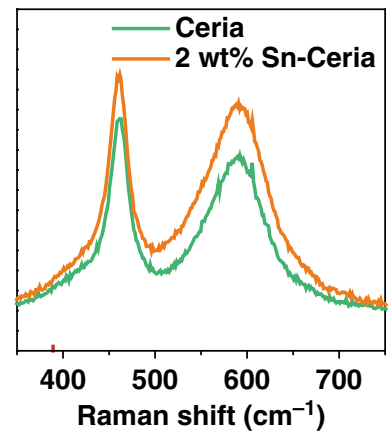

C

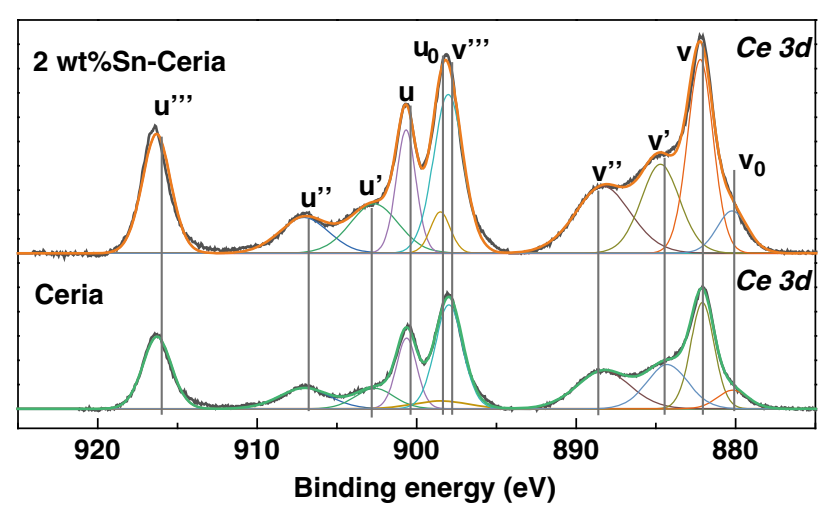

d
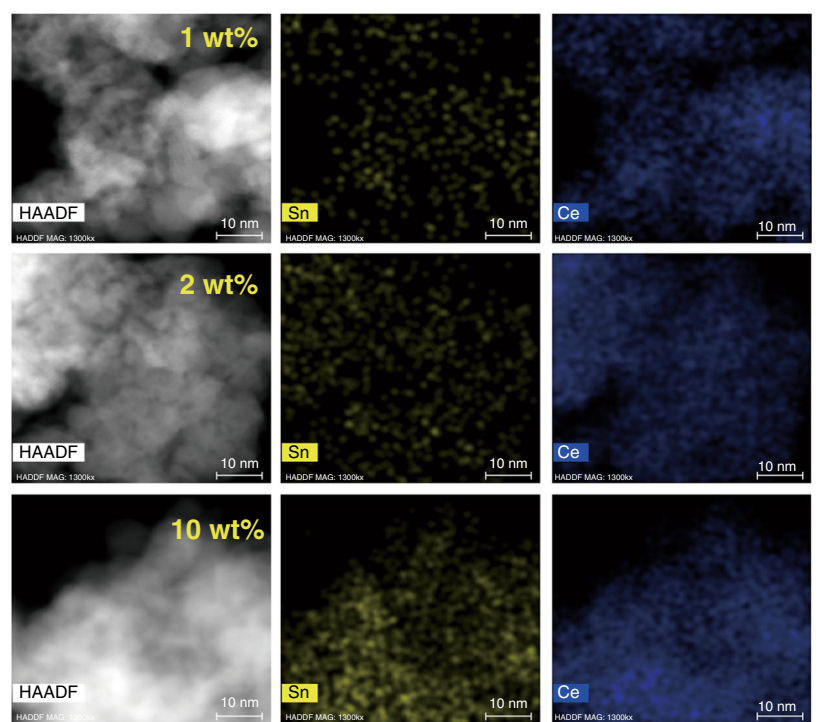

Fig. 2 Characterizations of ceria and Sn-ceria catalysts. a XRD patterns (using $\mathrm{Cu} \mathrm{K} \alpha$ radiation) of ceria and $\mathrm{Sn}$-ceria catalysts with various $\mathrm{Sn}$ loading ranging from 1 wt $\%$ to 20 wt\%. b UV-Raman spectra of ceria (green line) and 2 wt\% Sn-Ceria (orange line). c XPS spectra for Ce $3 d$ core level of pristine ceria and 2 wt\% Sn-ceria. d TEM and EDS elemental mapping images ( $\mathrm{Ce}$ and $\mathrm{Sn}$ ) of 1 wt\%, 2 wt\%, and 5 wt\% Sn-ceria catalysts. Scale bar, $10 \mathrm{~nm}$

ceria by hydrogen to produce oxygen vacancies, (iv) water dissociation on the oxygen vacancies to produce active oxygen $\left(\mathrm{O}^{*}\right)$ and hydrogen, (v) aldol condensation of butanal to hydroxyaldehyde, (vi) reaction of hydroxyaldehyde with $\mathrm{O}^{*}$ to form surface-adsorbed carboxylate, and finally, (vii) dehydrogenation and decarboxylation of the carboxylate to obtain $4-\mathrm{HPO}^{14}$. In order to confirm the role of water in the oxygenate conversion process, isotope labeling experiments were conducted over ceria at $400{ }^{\circ} \mathrm{C}$. Upon injecting $\mathrm{D}_{2} \mathrm{O}$ to the pretreated ceria in $\mathrm{H}_{2}$ at

$400^{\circ} \mathrm{C}$, hydrogen deuteride and deuterium ( $\mathrm{HD}$ and $\mathrm{D}_{2}$ ) are observed (Supplementary Figure 5), indicating that the water dissociates at the oxygen vacancies on the ceria surface to produce hydrogen and heal the defects ${ }^{15,16}$. When a mixture of $n$-butanol and $\mathrm{D}_{2} \mathrm{O}(5 \mathrm{~mL}$ and $1 \mathrm{~mL}$, respectively) was injected and carried to the catalyst bed by Ar gas, the formation of $\mathrm{H}_{2}(\mathrm{~m} / \mathrm{z}=2)$, HD $(\mathrm{m} / \mathrm{z}=3), \mathrm{D}_{2}(\mathrm{~m} / \mathrm{z}=4)$, and $\mathrm{CO}_{2}(\mathrm{~m} / \mathrm{z}=44)$ was immediately detected by on-line mass spectrometry, which confirms the role of water in the transformation of $n$-butanol. In all of the conducted five pulses, $\mathrm{HD}$ and $\mathrm{D}_{2}$ were detected (Fig. 1(c)).

To elucidate the reaction pathways for forming 4-HPO, ceriacatalyzed reactions with different mixed oxygenate substrates were conducted. For the substrate without $n$-butanol, condensation of acetone and ethanol can produce 4-HPO over ceria. The feed containing only ethanol generated $38 \%$ acetone, $31 \% 2$ pentanone, $20 \%$ 2-pentanol, and $11 \% n$-butanol in the liquid ${ }^{17}$. The condensation of 2-pentanone and ethanol selectively generated 4-HPO, confirmed by co-feeding 2-pentanone, and ethanol (Supplementary Figure 6). In addition, the feed containing only acetone resulted in self-condensation products of acetone, including $15 \%$ mesityl oxide, $7 \%$ isophorone, and the further isomerized (6\% 4-methylpent-4-en-2-one) or hydrogenated products (5\% 4-methylpentan-2-one). 3, 5-Dimethylphenol $(26 \%)$, formed via demethanation of isophorone, and its derivative (13\% 2, 4, 6-trimethylphenol), were also observed in the liquid phase ${ }^{18-20}$. However, this complex product distribution was not observed for ABE mixture conversion, suggesting that under our reaction condition, the condensation of acetone with ethanol is more favorable than the self-condensation of acetone. Acetone is a product of acetic acid ketonization reaction over acid-base catalysts ${ }^{21}$.

Interestingly, although ceria is a versatile catalyst for dehydrogenation, alcohol Guerbet reaction, condensation, and esterification reactions, all these reactions generate 4-HPO with high selectivity. Figure 1(d) illustrates the complicated reaction network with the feedstock of acetone, $n$-butanol, ethanol, and water, which could be summarized as follows:

(1) $n$-Butanol can be dehydrogenated to butanal, which reacts with water on reduced ceria catalyst to form 4-HPO, as confirmed by the result of co-feeding of butanal and water (Supplementary Figure 7).

(2) Besides acting as reactant, $n$-butanol is also a product generated via ethanol Guerbet reaction, from which 4-HPO was produced via route (1).

(3) $n$-Butanol can be dehydrogenated to butanal, and then to butyl butyrate via esterification of $n$-butanol and butanal. The reaction of butyl butyrate and water generates 4-HPO, experimentally confirmed by the co-feeding of butyl butyrate and water (Supplementary Figure 8).

(4) Dehydrogenation of ethanol produces acetaldehyde, which then condenses with acetone to give 2-pentanone, whose further condensation with ethanol produces 4-HPO.

Catalyst synthesis and characterization. From the above discussion, it is noteworthy that aldehydes produced by the dehydrogenation of ethanol and $n$-butanol are important precursors for selective 4-HPO generation. Promoters were introduced to ceria, to further enhance the dehydrogenation ability, including a series of metal oxides such as $\mathrm{MgO}, \mathrm{ZnO}, \mathrm{Fe}_{2} \mathrm{O}_{3}$, and $\mathrm{SnO}_{2}$. In the $n$-butanol dehydrogenation reaction (Supplementary Figure 9 (a)), butanal, which is a key intermediate for 4-HPO generation, was the major product obtained over these metal oxide catalysts, among which $\mathrm{SnO}_{2}$ offers the best selectivity toward butanal (over $99 \%)$. We then prepared a series of Sn-modified ceria catalysts with different approaches (marked A, B, C, and D) and employed 
them in aqueous ABE conversion (Supplementary Figure 9 (b)). Among these catalysts, the Sn-doped ceria catalyst (marked as Snceria) prepared by co-precipitation (style D), showed the highest selectivity toward 4-HPO and the best catalytic stability (Supplementary Figure 9 (c)), the optimal loading for Sn being $2 \mathrm{wt} \%$ (Supplementary Figure 10). For comparison, 2 wt\% In-, Fe-, and $\mathrm{Zn}$-doped ceria catalyts were also prepared with the similar method. All of them showed less efficient catalytic performances with either moderate conversion or lower selectivity of 4-HPO (Table 1). Ceria can provide redox sites especially oxygen vacancies, for the condensation, esterification, and Guerbet reactions, whereas tin is proposed to promote catalytic hydrogen removal. We conducted X-ray diffraction (XRD), inductively coupled plasma (ICP) analysis, $\mathrm{N}_{2}$ adsorption-desorption, and transmission electron microscopy (TEM) experiments to characterize the best Sn-ceria catalysts (Fig. 2, Supplementary Figure 11-13, Supplementary Table 3-5). From the XRD profile, only the cubic phase of ceria is observed with Sn loading $\leq 5 \mathrm{wt} \%$ (please note the $5 \mathrm{wt} \%$ means that the weight loading of Sn added to the ceria catalyst is $5 \mathrm{wt} \%$, whereas the loading amounts of the corresponding catalysts, determined by ICP, can be found in Supplementary Table 3). In contrast, the $\mathrm{SnO}_{2}$ phase appeared when $10 \mathrm{wt} \%$ and $20 \mathrm{wt} \% \mathrm{Sn}$ was doped into the ceria catalysts (Fig. 2(a)). This indicates that when the loading of Sn is not too high, the tin species are highly dispersed over the ceria surface. The highly dispersed state of the tin species on $2 \mathrm{wt} \% \mathrm{Sn}$-ceria catalyst is further confirmed by TEM observations and energy dispersive spectroscopic elemental mappings, which show that the tin species are almost homogeneously distributed over the ceria surface and no aggregation or sintering of $\mathrm{Sn}$ is identified (Fig. 2(d)). This highly dispersed tin species may accelerate the dehydrogenation of the complex reaction network of $\mathrm{ABE}$ mixture transformation and drive the reaction towards 4-HPO. Furthermore, UV-Raman spectra are found to be dominated by the strong $\mathrm{F}_{2 \mathrm{~g}}$ mode of the ceria fluorite phase at $462 \mathrm{~cm}^{-1}$ and a band at $592 \mathrm{~cm}^{-1}$ due to the defect-induced (D) mode for both ceria and $2 \mathrm{wt} \%$ Sn-ceria (Fig. 2(b)). The relative intensity ratio of $I_{\mathrm{D}} / I_{\mathrm{F} 2 \mathrm{~g}}$ (concentration of oxygen vacancy) is about 0.86 for $2 \mathrm{wt} \%$ Sn-ceria, which is a little higher than that for ceria $(0.81)$, indicating that $\mathrm{Sn}$ addition promoted the formation of oxygen vacancies, as confirmed by the higher concentration of Ce(III) in 2 wt $\%$ Sn-ceria than pristine ceria $(32.8 \%$ vs. $23.3 \%$, Fig. $2($ c) $)$. Both the highly dispersed tin species and oxygen vacancies are critical for the good catalytic performance obtained.

Effects of feedstock. Different bacteria and fermentation technologies generate $\mathrm{ABE}$ solutions with different concentrations and compositions ${ }^{1}$. Thus, it is imperative to know the effect of water content on this reaction process. We conducted the reaction using three artificial aqueous $\mathrm{ABE}$ solutions with different water contents $\left(623 \mathrm{gL}^{-1}, 707 \mathrm{gL}^{-1}\right.$, and $\left.783 \mathrm{gL}^{-1}\right)$, selected based on the representative water content that can be obtained by current separation techniques reported in literature (Supplementary Figure 14). In all the cases, the selectivity towards 4$\mathrm{HPO}$ is higher than $80 \%$. Apart from substrate concentration, the ratio of different oxygenates might also have an impact on the reaction. We tested an aqueous $\mathrm{ABE}$ solution with different reactant ratios (e.g.: A:B:E mass ratio $=3: 6: 1$, water content: $\sim 20 \mathrm{wt} \%$, to simulate fermentation by Clostridium acetobutylicum) and observed that 4 -HPO selectivity of $~ 68 \%$ and yield of $\sim 55 \%$ can be obtained, suggesting the pervasiveness of the current method (Table 1). In addition, organic acids, mainly acetic acid and butyric acid, are usually produced during $\mathrm{ABE}$ fermentation ${ }^{2,22}$. Here, the addition of acetic acid and butyric acid ( $1.7 \mathrm{wt} \%$ and $1.5 \mathrm{wt} \%$, respectively) increased 4 -HPO selectivity from $84 \%$ to $90 \%$ (Supplementary Figure 15 ).

Catalytic stability. To test the catalyst stability, we performed a continuous reaction by using $2 \mathrm{wt} \% \mathrm{Sn}$-ceria (Fig. 3(a)). Initially, 4 -HPO was produced with $\sim 70 \%$ conversion and $~ 86 \%$ selectivity. After about $300 \mathrm{~h}$, the average 4 -HPO selectivity was maintained at $85 \%$ with $50 \%$ conversion and $>90 \%$ carbon balance. The cold-trapped liquid phase naturally separates into two layers (Fig. 3(b)), easily separable in a separatory funnel. Phase (A) contains 4-HPO, 2-pentanone, unreacted acetone, and nbutanol, while phase (B) mainly contains unreacted acetone and water (Supplementary Figure Figure 16). High purity of 4-HPO ( $>95 \%$ ) can be obtained by fractional distillation of phase (A), showing the power of current process (Supplementary Figure 17). After $300 \mathrm{~h}$ of reaction, extensive shrinkage was observed in the catalyst surface area, possibly due to carbonaceous deposition, which are the main reasons for the slight deactivation of the catalyst (Supplementary Figure 18-20). Developing highly stable tin-ceria-based catalyst system is the next goal of this biomass transformation process.

In summary, herein we have developed a strategy for the catalytic conversion of aqueous $\mathrm{ABE}$ solutions to phase-separable 4 -HPO with $\sim 86 \%$ selectivity and $\sim 70 \%$ conversion over Sn-ceria catalyst. The presence of water was critical for this highly selective catalytic system. Sn-modified ceria serves as a versatile catalyst for the complicated catalytic reaction network and all the catalyzed reactions yield 4-HPO with high selectivity. This system paves a path for effective biomass conversion to obtain value-added products.

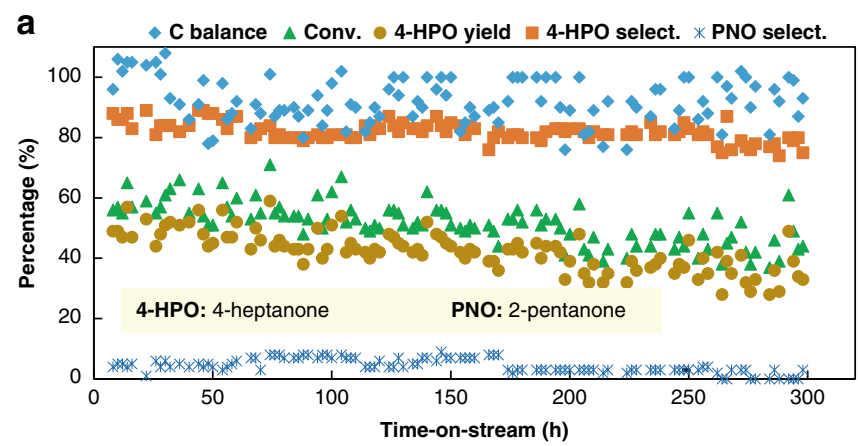

b

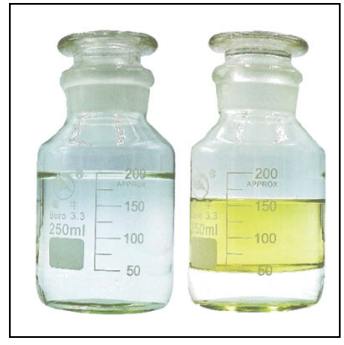

Fig. 3 Stability test of 2 wt\% Sn-ceria catalyst in aqueous ABE solution conversion reaction. a Catalytic stability test result. Catalyst (3.2 g, $40-60$ mesh), $\mathrm{N}_{2}$ as carrier gas $\left(10 \mathrm{~mL} \mathrm{~min}^{-1}\right), 420^{\circ} \mathrm{C}, \mathrm{WHSV}=0.5 \mathrm{~h}^{-1}$. ABE solution as feedstock with A:B:E:water ratio of 9:51:1:22 (by weight). b Images of $A B E$ feedstock (left) and trapped liquid products (right) 


\section{Data availability}

All data are available from the corresponding author upon reasonable request.

Received: 29 August 2018 Accepted: 10 November 2018

Published online: 05 December 2018

\section{References}

1. Tashiro, Y., Yoshida, T., Noguchi, T. \& Sonomoto, K. Recent advances and future prospects for increased butanol production by acetone-butanol-ethanol fermentation. Eng. Life Sci. 13, 432-445 (2013)

2. Kujawska, A., Kujawski, J., Bryjak, M. \& Kujawski, W. ABE fermentation products recovery methods-a review. Renew. Sust. Energ. Rev. 48, 648-661 (2015).

3. Alamillo, R., Crisci, A. J., Gallo, J. M. R., Scott, S. L. \& Dumesic, J. A. A tailored microenvironment for catalytic biomass conversion in inorganic-organic nanoreactors. Angew. Chem. Int. Ed. 52, 10349-10351 (2013).

4. Orozco, L. M., Renz, M. \& Corma, A. Carbon-carbon bond formation and hydrogen production in the ketonization of aldehydes. ChemSusChem $\mathbf{9}$, 2430-2442 (2016).

5. Sacia, E. R. et al. Highly selective condensation of biomass-derived methyl ketones as a source of aviation fuel. ChemSusChem 8, 1726-1736 (2015).

6. Huber, G. W., Chheda, J. N., Barrett, C. J. \& Dumesic, J. A. Production of liquid alkanes by aqueous-phase processing of biomass-derived carbohydrates. Science 308, 1446-1450 (2005).

7. Kunkes, E. L. et al. Catalytic conversion of biomass to monofunctional hydrocarbons and targeted liquid-fuel classes. Science 322, 417-421 (2008).

8. Liu, D. J., Zhang, Y. T. \& Chen, E. Y. X. Organocatalytic upgrading of the key biorefining building block by a catalytic ionic liquid and $\mathrm{N}$-heterocyclic carbenes. Green. Chem. 14, 2738-2746 (2012).

9. Wilson, J. \& Chen, E. Y. X. Organocatalytic cross-coupling of biofuranics to multifunctional difuranic C-11 building blocks. Acs Sustain. Chem. Eng. 4, 4927-4936 (2016).

10. Harvey, B. G. et al. Renewable thermosetting resins and thermoplastics from vanillin. Green. Chem. 17, 1249-1258 (2015).

11. Zang, H. J. et al. Catalytic coupling of biomass-derived aldehydes into intermediates for biofuels and materials. Catal. Sci. Technol. 8, 1777-1798 (2018).

12. Anbarasan, P. et al. Integration of chemical catalysis with extractive fermentation to produce fuels. Nature 491, 235-239 (2012).

13. Wang, Y. H. et al. Heterogeneous ceria catalyst with water-tolerant Lewis acidic sites for one-pot synthesis of 1,3-diols via Prins condensation and hydrolysis reactions. J. Am. Chem. Soc. 135, 1506-1515 (2013).

14. Nishiguchi, T. et al. Catalytic steam reforming of ethanol to produce hydrogen and acetone. Appl. Catal. A Gen. 279, 273-277 (2005).

15. Rodriguez, J. A. et al. Activity of $\mathrm{CeO}_{x}$ and $\mathrm{TiO}_{x}$ nanoparticles grown on $\mathrm{Au}$ (111) in the water-gas shift reaction. Science 318, 1757-1760 (2007).

16. Montini, T., Melchionna, M., Monai, M. \& Fornasiero, P. Fundamentals and catalytic applications of $\mathrm{CeO}_{2}$-based materials. Chem. Rev. 116, 5987-6041 (2016).

17. Moore, C. M. et al. Acetaldehyde as an ethanol derived bio-building block: an alternative to Guerbet chemistry. Green. Chem. 19, 169-174 (2017).

18. Faba, L., Diaz, E. \& Ordonez, S. Gas phase acetone self-condensation over unsupported and supported $\mathrm{Mg}-\mathrm{Zr}$ mixed-oxides catalysts. Appl. Catal. B Environ. 142, 387-395 (2013).
19. Quesada, J. et al. Role of surface intermediates in the deactivation of $\mathrm{Mg}-\mathrm{Zr}$ mixed oxides in acetone self-condensation: a combined DRIFT and ex situ characterization approach. J. Catal. 329, 1-9 (2015).

20. Moore, C. M. et al. Synthesis of acetone-derived C-6, C-9, and C-12 carbon scaffolds for chemical and fuel applications. Chemsuschem 9, 3382-3386 (2016).

21. Gliński, M., Kijeński, J. \& Jakubowski, A. Ketones from monocarboxylic acids catalytic ketonization over oxide systems. Appl. Catal. A Gen. 128, 209-217 (1995).

22. Thang, V. H., Kanda, K. \& Kobayashi, G. Production of acetone-butanolethanol $(\mathrm{ABE})$ in direct fermentation of cassava by Clostridium saccharoperbutylacetonicum N1-4. Appl. Biochem. Biotechnol. 161, 157-170 (2010).

\section{Acknowledgements}

This work received financial support from the "Strategic Priority Research Program of the Chinese Academy of Sciences" (XDB17000000, XDB17020300), the National Key R\&D Program of China (2017YFB0602200), and the Natural Science Foundation of China $(21721004,21690080,21711530020,21725301,91645115,21473003,21673273$, 21872163 , and 21821004).

\section{Author contributions}

F.W. and D.M. designed the study. Y.W., J.Z. and Z.Z. performed most of the reactions. Y.W., M.P. and J.A. did the data analysis. Y.W., M.P., D.M. and F.W. wrote the paper. S.D., H.A., F.F., and X.L. conducted the experiments of XPS, Raman, and TEM. P.Z. provided reagents and revised the paper.

\section{Additional information}

Supplementary Information accompanies this paper at https://doi.org/10.1038/s41467018-07593-0.

Competing interests: The authors declare no competing interests.

Reprints and permission information is available online at http://npg.nature.com/ reprintsandpermissions/

Publisher's note: Springer Nature remains neutral with regard to jurisdictional claims in published maps and institutional affiliations.

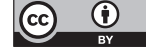

Open Access This article is licensed under a Creative Commons Attribution 4.0 International License, which permits use, sharing, adaptation, distribution and reproduction in any medium or format, as long as you give appropriate credit to the original author(s) and the source, provide a link to the Creative Commons license, and indicate if changes were made. The images or other third party material in this article are included in the article's Creative Commons license, unless indicated otherwise in a credit line to the material. If material is not included in the article's Creative Commons license and your intended use is not permitted by statutory regulation or exceeds the permitted use, you will need to obtain permission directly from the copyright holder. To view a copy of this license, visit http://creativecommons.org/ licenses/by/4.0/.

(c) The Author(s) 2018 